\title{
Teaching Strategies of Specialized English for Automation Assisted by Multimedia and Network
}

\author{
Xiyan Wang, Tianhao Wang \\ Foreign Language Institute, Northeast Dianli University, Jilin, 132012 China
}

\begin{abstract}
Specialized English is a very important course for the college students majored in science. Based on the current teaching status, this course needs more attention of the college students and the teachers. It can help the students to keep pace with the current advanced technology as well as the communication with others. This thesis is explored with the characteristics of the specialized English and the English classes assisted by the multimedia and network, according to which, the author puts forward some advice on the teaching strategies of the specialized English classes in order to improve the teaching effects.
\end{abstract}

Keywords-teaching strategies; multimedia and network; specialized English for automation.

\section{CHARACTERISTICS OF SPECIALIZED ENGLISH FOR AUTOMATION}

Specialized English is the scientific English used in a special major. The purpose of the specialized English course is to understand and translate the scientific materials with much professional knowledge as well as some specialized terms. With the development of automation technology, a lot of outstanding simulation software, latest research papers, some textbooks of this major are written in English. With the wide spread of the bilingual teaching, students are aware of the importance of specialized English. Without the basic specialized vocabulary, a student with the CET 6 certificate can't get the general idea of the instructions in English.

One of the most distinctive features of specialized English is its technical terms, which not only account for a large part of English vocabulary, but also are the most important source of newly coined words in modern English, ranging over an extensive area of various fields. The mastery of them will benefit us a great deal in the translation of specialized English. According to the classification of technical words, there are singles words, compound forms and set phrases. Most words are formed by derivation, compounding, blending, shortening and borrowing. Though specialized English consists of large amount of professional terms, these terms are derived or transformed from the basic English vocabulary, for example, feedback, openloop, conductor, semiconductor and so on. Therefore, the same word used in the daily life and the professional passages are different in meaning and usage.

As to the grammatical features, there are some characteristics in the scientific passages. To be objective and accurate as much as possible, the concise forms of sentences are well appreciated. The passive voice and nonfinite verb forms are widely used. The elliptical sentences are frequently used, as well as the imperative sentences. The sentences with it as its formal subject are the most important ones.

As to the rhetoric feature, on the one hand, the simple present tense is widely used because the scientific passages are focus on the observation, experiment and the objective rules and characteristics. The content is consistent whenever it is. On the other hand, there are more diagrams, data and formats used to describe the concept, the principles and the theories. The vocabulary such as although, because, however, due to, thus and etc. is frequently used to analyze and discuss on a certain topic.

Students should be familiar with the main characteristics of the scientific papers listed above. Then they could be directed when doing the long reading comprehensions. First, they should pay attention to the sentences in the passive voice. Second, the meaning of the long sentence should be understood according to the context. The long sentences should be analyzed according to the grammar structures. Third, students should understand the whole passage generally and deeply.

\section{CHARACTERISTICS OF THE ENGLISH CLASSES ASSISTED BY MULTIMEDIA AND NETWORK}

Multimedia refers to content that uses a combination of different content forms. This contrasts with media that use only rudimentary computer displays such as text-only or traditional forms of printed or hand-produced material. Multimedia includes a combination of text, audio, still images, animation, video, or interactivity content forms. The characteristics of multimedia applied in English classes are as followed:

\section{A. To arouse the great interests of learning English}

"According to the educational psychology, the key factor in learning is the emotion control. The main factors of emotion control in foreign language learning are motivation, attitude and personality."[1] The traditional teaching methods are composed of the chalk, the blackboard, the tape recorder and the books which are very boring. The students are always lack of interests in learning. However, with the help of multimedia, the class could be organized vividly by the PPT show, the audio and video materials which could stimulate the students' senses to enlarge their eyesight. They are keen on this new form of English teaching. They could 
select the information or the type as they like to keep on learning with more knowledge.

\section{B. To enrich the content of classes}

In the traditional classes, either the teaching part or the exercise part could hardly arouse the interests of the students. Because of the various contents played by the multimedia, such as the audio, the video, the text, the animation and so on, these forms could display a vivid class in front of the students. Teachers could choose the materials preferred by the students from the Internet. All these efforts could be proved by the multimedia. If the teachers could use some teaching software, the teaching effect will be better.

The multimedia applied in English teaching could save a lot of time in class. The different types of materials could add the quantity of information in class, which could help to raise the efficiency of teaching. The multimedia applied in English teaching can not only fulfill the teaching task, but also help to promote the reform and regeneration in education. This kind of English classes offer a proper environment to the education for all-round development.

\section{To promote the teachers' comprehensive abilities}

The multimedia requires that the teachers not only be proficient in English but also be skillful in operating the computer. The methods of making the courseware are widely used in college English classes. In the summer training of the college English teachers, the lectures on this topic are warmly welcomed. In the daily life teachers should accumulate the proper pictures, the interesting videos and some funny jokes which are related to the classes. When making the courseware, the teachers should hold the modest attitude to learn from each other and to share with each other. [2]

\section{SPECIALIZED ENGLISH FOR AUTOMATION ASSISTED BY MULTIMEDIA AND NETWORK}

The application of multimedia and network in specialized English teaching could be done in the following aspects:

\section{A. Various forms of information}

Making use of the multimedia classes, teachers should display as much information as possible to the students. The bright colors, the delightful images, the proper movement and the lively sound could help to arouse the interests of the students. Once they are keen on English classes, the teaching effects will be improved. The multimedia is used to produce computer-based training courses and reference books like encyclopedia and almanacs. The user could go through a series of presentations, text about a particular topic, and associated illustrations in various information formats. Teachers should design the courseware according to the teaching plans and period. In the revised courseware, the pictures, the sound, the animation and the videos should be made fully use of to stimulate the students' brains and to make the abstract knowledge into concrete and interesting. The content of the courseware should be focus on the introduction of the translation theories and the details of translation skills. Students always feel puzzled about the formation of the technical terms. Teachers could make use of the courseware. The vocabulary courseware could be designed from their familiar words to the new technical terms. The formation could be showed step by step. Students will find it easy to memorize the new technical terms.

\section{B. Large quantity of information}

Before giving the lectures on some scientific principles, teachers should introduce the background information to the students. They can get the general idea about what is going to be discussed or talked about. This kind of communication is carried on either between the teacher and students or among the students. By the discussion and interactivities, students are well prepared to the class. The background information could be shown in many types, such as the pictures, the videos, the power point and so on. If the students can finish the task by groups, the teaching effect will be better. [3]

Teachers could also show the analysis of the sentences or passages by the power points. Students would understand the long sentences easily in such a concrete way. Different levels of the passage could also be shown in such a way. The thinking patterns and the viewpoints of the author could be analyzed with the direction of the teachers. For some scientific papers, the operation of a certain machine or equipment could be displayed with some videos. It could help the students to understand such passages deeply

There are still some matters need great attention. First, a lot of teachers take the screen as the former blackboard. The courseware is so boring that there is no sound or video in it. A lot of questions are asked and students are passively keeping notes. They find the class is as boring as before. Second, teachers play the power point so quickly that some students can't follow the pace to keep notes. Teachers should also pay attention to the size of the letters, the reaction of the students as well as the quality of the pictures used in the courseware to maintain the best teaching effect. Third, teachers should improve their computer level. Some teachers can't make the courseware or play the content prepared. There may be something wrong with the equipment. However, the teacher could give a better class without any influence of the technical problems if his computer skill is better.

\section{CONCLUSION}

The application of multimedia and network in specialized English teaching is relatively new in the teaching reforms. Based on the characteristics of the technical English and the multimedia, teachers should adjust the teaching style and computer skills. To arouse the interests of the students, the multimedia and the network should be made fully use of. To cultivate the language ability and the autonomic learning is the purpose of English teaching. Because of the limited space here, the author discussed the teaching strategies of the specialized English assisted by multimedia and network in this thesis. More researches should be done in other aspects in the future. 


\section{REFERENCES}

[1] Shu Dingfang, Zhuang Zhixiang: Modern Foreign Language Teaching [M].Shanghai Foreign Language Education Press (1996), p.46-50.
[2] Yang Yuchun, ZhangYang, Analysis of Advantages and Disadvantages in Multimedia Applied in College English Teaching, [J], Read and Write Periodical (2014).

[3] Xu Qiuling, CALL Applied in English Listening Teaching, [J] Journal of Shandong Youth Administrative Cadres College (2006). 